\title{
Determination of Antioxidant Capacity of Unprocessed and Processed Food Products by Spectrophotometric Methods
}

\author{
Aleksandra Szydłowska-Czerniak • \\ Agnieszka Tułodziecka • Edward Szlyk
}

Received: 12 July 2011 / Accepted: 30 September 2011 /Published online: 15 October 2011

(C) The Author(s) 2011. This article is published with open access at Springerlink.com

\begin{abstract}
Two electron transfer (ET) reaction-based methods, ferric reducing antioxidant power (FRAP) and Folin-Ciocalteu (FC) reducing capacity, were used for the determination of total antioxidant capacity of vegetable oils (rapeseed, palm and extra virgin olive oils), meat samples (poultry and pork) and potatoes before and after the frying process under domestic frying conditions. Before frying, potatoes had the highest FRAP value $(276.7 \mu \mathrm{mol}$ Trolox/100 g), whereas extra virgin olive oil revealed the highest FolinCiocalteu Index $(\mathrm{FCI}=443.2 \mu \mathrm{mol}$ Trolox/100 g). Antioxidant capacity of methanolic extracts of raw meat (9.0-9.4 $\mu \mathrm{mol}$ Trolox/100 $\mathrm{g}$ and 135.7-160.1 $\mu \mathrm{mol}$ Trolox/100 g for FRAP and FC methods, respectively) was lower than FRAP (133.4-149.6 $\mu$ mol Trolox/100 g) and FCI (156.2-443.2 $\mu \mathrm{mol}$ Trolox/100 g) of unheated rapeseed and extra virgin olive oils. However, antioxidant capacity of the studied food samples changed after frying process. Positive correlations (correlation coefficients ranged between 0.5742 and 0.9942 ) were found between the two analytical methods used to determine the antioxidant capacity of unprocessed and processed food products. The results of principal component analysis (PCA) indicate that there are differences between total amounts of antioxidants in raw and fried food products.
\end{abstract}

Keywords Antioxidant capacity $\cdot$ Foods $\cdot$ Frying process . Principal component analysis

A. Szydłowska-Czerniak $(\bowtie) \cdot$ A. Tułodziecka $\cdot$ E. Szłyk Faculty of Chemistry, Nicolaus Copernicus University,

7 Gagarin Street,

87-100 Toruń, Poland

e-mail: olasz@umk.pl

\section{Introduction}

Meats, vegetable oils and potatoes are an essential source of nutrients and biologically active compounds in human diet and are consumed in vast amounts in developed societies. Food antioxidants prevent several degenerative diseases, protecting body tissues against oxidative stress, and may be protective in vitro against several types of cancer (Gupta 2005). Potato polyphenols have potential antihypertensive activities and act as moderate angiotensin-converting enzyme inhibitors, and they exert hepatoprotective effects (Ševčík et al. 2009). Furthermore, antioxidant compounds in vegetable oils exhibit an antiradical activity, and they are important in prevention and treatment of the mentioned diseases (Szydłowska-Czerniak et al. 2008a; Tuberoso et al. 2007). Moreover, meats and their products are known as sources of endogenous enzymatic and non-enzymatic antioxidants (Jung et al. 2010; Moñino et al. 2008; Sacchetti et al. 2008).

Fried foods are very popular worldwide due to their delicious sensory characteristics. However, the frying process compared with other cooking processes reveals the same or even smaller effect on decrease of nutrients in food products (Gupta 2005).

Antioxidant capacity of unprocessed meat samples, potatoes and edible oils was mostly determined by the electron transfer (ET)-based methods such as ABTS (2,2'azinobis(3-ethylbenzothiaziline-6-sulfonate) (Ševčík et al. 2009; Moñino et al. 2008; Sacchetti et al. 2008; Descalzo et al. 2007; Descalzo and Sancho 2008; Lachman et al. 2009; Pellegrini et al. 2001; Teow et al. 2007), DPPH (2,2'diphenyl-1-picrylhydrazyl) (Ševčík et al. 2009; Tuberoso et al. 2007; Moñino et al. 2008; Lachman et al. 2009; Teow et al. 2007; Blessington et al. 2010; Chiou et al. 2009; Kalantzakis et al. 2006; Silva et al. 2010; Valavanidis et al. 
2004) and FRAP (ferric reducing antioxidant power) (Szydłowska-Czerniak et al. 2008a, b; Moñino et al. 2008; Descalzo et al. 2007; Descalzo and Sancho 2008; Lachman et al. 2009; Cheung et al. 2007; López-López et al. 2009). Also, Folin-Ciocalteu (FC) reagent was used for the determination of total phenolic compounds and other reducing species in unprocessed and processed vegetable oils, meats and potatoes (Ševčík et al. 2009; SzydłowskaCzerniak et al. 2008a, b; Jung et al. 2010; Pellegrini et al. 2001; Teow et al. 2007; Blessington et al. 2010; Kalantzakis et al. 2006; Silva et al. 2010; Valavanidis et al. 2004; Farhoosh et al. 2009). Moreover, the hydrogen atom transfer-based (HAT) method, oxygen radical absorbance capacity (ORAC), was proposed for the evaluation of antioxidant activities of vegetable oils (SzydłowskaCzerniak et al. 2008b; Hay et al. 2006), different meat samples (Wu et al. 2008) and potatoes (Teow et al. 2007; Rautenbach and Venter 2010). However, antioxidant capacity of edible oils, potatoes and meats after cooking procedures was analyzed only by the ABTS method (Ševčík et al. 2009; Pellegrini et al. 2001; Blessington et al. 2010; Silva et al. 2010; Valavanidis et al. 2004; Napolitano et al. 2008). These authors reported that antioxidant capacity of the unprocessed edible oils, meats and potatoes ranged between 2.0 and $55000.0 \mu \mathrm{mol}$ Trolox/ $100 \mathrm{~g}$, whereas antioxidant capacity of these food samples after cooking changed from 50.0 to $1682.0 \mu \mathrm{mol}$ Trolox/ $100 \mathrm{~g}$ depending on analytical methods and the cooking conditions.

Although antioxidants are relatively thermally stable compounds, the frying process of food products affect their antioxidant capacity (Ševčík et al. 2009; Blessington et al. 2010; Silva et al. 2010; Valavanidis et al. 2004; Napolitano et al. 2008).

On the other hand, thermal processing leads to significant compositional changes as a result of the Maillard reactions, caramelization and fat thermoxidation. Furthermore, compounds formed during heat treatments as a consequence of the Maillard reactions are known to possess antioxidative activity, and such compounds could impact overall oxidative stability of processed food products (Gökmen et al. 2009).

In addition, the FC reagent is non-specific to phenolic compounds as it can be reduced by many non-phenolic compounds (e.g. Maillard reaction products, aromatic amines, sulfur dioxide, etc.) and for that reason is not suitable for determination of "total phenolic content", unless interfering species are considered or removed. Therefore, the modified FC assay was proposed for the measurement of total reducing capacity of the studied food samples.

To the best of our knowledge, the FRAP method was not applied for determination of antioxidant capacity of meat, potatoes and edible oils after thermal treatment.
Therefore, in the present paper, the FRAP and FC methods after some modifications were employed for the determination of the total antioxidant capacity of the commercial vegetable oils, poultry meat, pork meat and potatoes before and after thermal treatment. Also, the effect of frying process on antioxidant capacity of oils, meats and potatoes was studied. Besides, correlations between antioxidant capacities of the analyzed food samples determined by two different analytical methods were examined and discussed. The FRAP results and Folin-Ciocalteu Indexes (FCI) were used as descriptors for principal component analysis (PCA) in order to differentiate the analyzed food samples.

\section{Materials and Methods}

\section{Reagents}

All reagents were of analytical or HPLC grade. 2,4,6-tris(2pyridyl)-s-triazine (TPTZ, 99\%) and Folin-Ciocalteu (FC) reagent (2 N) were purchased from Sigma-Aldrich (Poznan, Poland). Acetic acid, hydrochloric acid, sodium acetate, sodium carbonate, iron(III) chloride hexahydrate $\left(\mathrm{FeCl}_{3} \times 6 \mathrm{H}_{2} \mathrm{O}\right)$, Trolox (6-hydroxy-2,5,7,8-tetramethylchromane-2-carboxylic acid, TE) and methanol (99.8\%) were obtained from POCH (Gliwice, Poland).

\section{Instruments}

The UV-Vis spectra of solutions were measured using a Helios $\alpha$-UNICAM spectrophotometer (Unicam, Cambridge, UK) in a $1-\mathrm{cm}$ quartz cell. The shaker type 357 (Elpan, Lubawa, Poland), centrifuge MPW-310 (LABOMIX, Warsaw, Poland), homogenizer Omni Mixer (A.G.A. Analytical, Warsaw, Poland) and incubator SUP 3 (Zalmed, Warsaw, Poland) were used for samples preparation.

Samples

The refined rapeseed oil (RO, Poland), refined palm oil (PO, Poland), extra virgin olive oil with garlic (EVOO, Spain), raw poultry meat - chicken breast (Mpou, Poland), raw pork meat - ham (Mpor, Poland) and fresh potatoes (P, Poland) were purchased from local stores in the original packing [poly(ethylene terephthalate) (PET) or glass bottles]. All food samples were stored in a refrigerator at $8{ }^{\circ} \mathrm{C}$ prior to analysis.

\section{Frying Process}

Lean pork and poultry meat samples were sliced $(2 \times 2 \times$ $0.5 \mathrm{~cm})$ and kept in the polyethylene bags in the 
refrigerator. Also, before frying potatoes were peeled, washed, wiped and cut into strips $(0.8 \times 0.8 \times 2.5 \mathrm{~cm})$. Three different vegetable oils, rapeseed, palm and extra virgin olive oil, were used for frying of meats and potatoes. Each oil $(50 \mathrm{~g})$ was poured into $6.0-\mathrm{cm}$ diameter glass beakers and was heated up to $180 \pm 5{ }^{\circ} \mathrm{C}$. Then portions of $50 \pm 1 \mathrm{~g}$ of each meat sample or $8.0 \pm 1 \mathrm{~g}$ of potatoes were immersed and fried for $6 \mathrm{~min}$ (meat/oil ratio=1:1 and potatoes/oil= 1:6). The oil temperature was monitored with a digital thermometer. After frying, meats and potatoes were placed in a clean dry filter paper for $5 \mathrm{~min}$, allowing for the excess oil to drain. After processing, the studied oils and food products were taken for determination of their antioxidant capacity. All frying experiments were performed in triplicate using fresh vegetable oils and food products.

\section{Samples Preparation}

Methanol extracts from the unprocessed and processed oils, meats and potatoes were obtained. The samples of raw and fried meats and potatoes were homogenized before extraction. Then test tubes with the studied food samples (1.00-8.30 g) and solvent $(10 \mathrm{~mL})$ were shaken for $1 \mathrm{~h}$ at room temperature in the dark. The extracts were separated from food samples (for oils in a freezer below $-20{ }^{\circ} \mathrm{C}$ ) and transferred quantitatively into glass bottles. Each food sample was extracted in triplicate, and extracts were stored in a refrigerator at $8{ }^{\circ} \mathrm{C}$, prior to antioxidant capacity analyses.

\section{Antioxidant Capacity Determination}

\section{Ferric Reducing Antioxidant Power (FRAP) Method}

The spectrophotometric FRAP method was used for antioxidant capacity determination of the studied food samples according to Benzie and Strain with minor modifications (Benzie and Strain 1996). The FRAP reagent $-2.5 \mathrm{~mL}$ of a $10-\mathrm{mmol} / \mathrm{L}$ TPTZ solution in $40 \mathrm{mmol} / \mathrm{L} \mathrm{HCl}, 2.5 \mathrm{~mL}$ of $10 \mathrm{mmol} / \mathrm{L} \mathrm{FeCl}_{3}$ and $25 \mathrm{~mL}$ of $0.1 \mathrm{~mol} / \mathrm{L}$ acetate buffer $(\mathrm{pH} \mathrm{3.6)}$ - was prepared freshly and incubated at $40{ }^{\circ} \mathrm{C}$ for $15 \mathrm{~min}$. Then, $0.1-0.3 \mathrm{~mL}$ of methanolic extracts of food samples and $2 \mathrm{~mL}$ of FRAP reagent were transferred into a $10-\mathrm{mL}$ volumetric flask and made up to the volume with redistilled water. The obtained blue solutions were kept at room temperature for $10 \mathrm{~min}$ and centrifuged at $10,000 \mathrm{rpm}$ for $10 \mathrm{~min}$. The absorbance was measured at $593 \mathrm{~nm}$ against a reagent blank $(2 \mathrm{~mL}$ of FRAP reagent made up to $10 \mathrm{~mL}$ with redistilled water).

\section{Folin-Ciocalteu Reducing Capacity (FC) Method}

Total reducing capacity of the unprocessed and processed food samples was determined using the Folin-Ciocalteu
(FC) spectrophotometric method with some modifications (Singleton and Rossi 1965). Briefly, $1 \mathrm{~mL}$ of methanolic extract was transferred into a $10-\mathrm{mL}$ calibration flask, $0.5 \mathrm{~mL}$ of Folin-Ciocalteu reagent was added, the mixture was shaken for $3 \mathrm{~min}$, and $1 \mathrm{~mL}$ of saturated sodium carbonate solution $(22.0 \%)$ was added and made up to the mark with redistilled water. After $1 \mathrm{~h}$, solutions were centrifuged at 10,000 rpm (15 min), and absorbance at $765 \mathrm{~nm}$ was measured against a reagent blank.

\section{Calibration Curves}

Calibration curves were prepared using working methanolic solutions of Trolox containing $1.0 \times 10^{-3}-1.8 \times 10^{-2}$ and $7.6 \times 10^{-3}-1.5 \times 10^{-1} \mu \mathrm{mol} \mathrm{TE} / \mathrm{mL}$ for FRAP and FC methods, respectively. Five calibration curves for each method were plotted on the same day. The least-squares method was applied to calculate the lines: $y=(42.97 \pm 0.29) x$ $+(0.002 \pm 0.003)$ for FRAP method and $y=(5.97 \pm 0.08) x+$ $(0.083 \pm 0.007)$ for FC assay. The correlation coefficients were 0.999 and 0.998 for FRAP and FC methods, respectively. The relative standard deviations (RSD, $n=3$ ) of the slope were $0.5 \%$ for FRAP method and $1.5 \%$ for FC assay. The within-day precision of the proposed method was tested by analyzing three replicate samples containing $8.0 \times 10^{-3}$ and $5.7 \times 10^{-2} \mu \mathrm{mol} \mathrm{TE} / \mathrm{mL}$ for FRAP and FC methods, respectively. The obtained values of RSD $(0.8 \%$ for FRAP method and $1.0 \%$ for FC assay) indicate reasonable repeatability of these analytical methods. The proposed FRAP method appeared to be more sensitive $(\varepsilon=$ $4.32 \times 10^{4} \mathrm{dm}^{3} \mathrm{~mol}^{-1} \mathrm{~cm}^{-1}$ ) than the modified FC method $\left(\varepsilon=1.66 \times 10^{4} \mathrm{dm}^{3} \mathrm{~mol}^{-1} \mathrm{~cm}^{-1}\right)$. Moreover, the calculated detection $\left(\mathrm{DL}=3.8 \times 10^{-4} \mu \mathrm{mol} \mathrm{TE} / \mathrm{mL}\right.$ and $5.5 \times 10^{-3} \mu \mathrm{mol}$ $\mathrm{TE} / \mathrm{mL}$ for FRAP and $\mathrm{FC}$ methods, respectively) and quantification limits $\left(\mathrm{QL}=1.2 \times 10^{-3} \mu \mathrm{mol} \mathrm{TE} / \mathrm{mL}\right.$ for FRAP and $1.8 \times 10^{-2} \mu \mathrm{mol} \mathrm{TE} / \mathrm{mL}$ for $\mathrm{FC}$ assay) confirm linearity concentrations ranges for total antioxidant capacity determinations of the studied food samples.

\section{Statistical Analysis}

Antioxidant capacity of the studied food samples ( 3 portions from each of three frying processes, $n=9$ extracts) was determined within 1 day by the proposed FRAP and FC assays. The obtained results were presented as mean $(c) \pm$ standard deviation (SD). The Pearson correlation test was used to determine the correlation between FRAP and FCI results. Differences of $p<0.05$ were considered significant. One-way ANOVA, followed by Duncan test, was performed to analyze the significant differences between data $(p<0.05)$.

Principal component analysis was performed for the antioxidant capacity results of the unprocessed and processed food products using the Statistica (Windows 
software package) (version 8.0, 2007). A PCA score plot was used to determine whether various food samples could be grouped into different classes.

\section{Results and Discussion}

Antioxidant Capacity of Oils, Meats and Potatoes

The results of antioxidant capacity of the unprocessed and processed food products determined by FRAP and FC methods are listed in Tables 1 and 2.

Among the unprocessed vegetable oils, rapeseed oil revealed the highest FRAP value (149.6 $\mu \mathrm{mol}$ TE/ $100 \mathrm{~g}$ ), whereas antioxidant potential of palm oil determined by the same method (113.4 $\mu \mathrm{mol} \mathrm{TE} /$ $100 \mathrm{~g}$ ) was the lowest (Table 1). Previously, similar FRAP results of rapeseed $(95.6-150.9 \mu \mathrm{mol} / 100 \mathrm{~g})$ and extra virgin olive oils $(107.0-163.6 \mu \mathrm{mol} / 100 \mathrm{~g})$ were reported by Szydłowska-Czerniak et al. (SzydłowskaCzerniak et al. 2008a,b). FRAP values of the discussed oils were higher when compared to results obtained by Cheung et al. (40.0 and $15.3 \mu \mathrm{mol} / 100 \mathrm{~g}$ for canola and olive oil, respectively) (Cheung et al. 2007).

It is noteworthy that, unheated extra virgin olive oil has significantly higher FCI $(443.2 \mu \mathrm{mol} \mathrm{TE} / 100 \mathrm{~g})$ than rapeseed oil $(156.2 \mu \mathrm{mol} \mathrm{TE} / 100 \mathrm{~g})$ and palm oil (48.0 $\mu \mathrm{mol}$ TE/100 g) (Duncan test). The obtained FRAP and FCI results of the studied edible oils indicated that frying process caused an 11-68\% decrease in the antioxidant capacities (Table 1). It can be noted that the highest decrease in the AC determined by FRAP took place during frying pork meat and potatoes in rapeseed oil $(68 \%$ and $63 \%$, respectively), whereas the frying process of these food samples caused only $28 \%$ and $23 \%$ decrease of FCI of extra virgin olive oil (Table 1). Antioxidant capacity of the processed vegetable oils decreased due to degradation of the antioxidant compounds in the oils during frying at high temperature. Somewhat higher reduction of polyphenols amount in olive oils processed at $180^{\circ} \mathrm{C}$ with potatoes $(60$ $80 \%)$ and beef meat (70-80\%) was reported by Silva et al. (Silva et al. 2010). For comparison, the radical-scavenging activity (RSA) and total phenolic content (TPC) in olive oils decreased during heating processes $(\mathrm{RSA}=105$ $297 \mu \mathrm{mol} \mathrm{TE} / 100 \mathrm{~g}$ and $\mathrm{TPC}=2.5-32.6 \mathrm{mg} / 100 \mathrm{~g}$, and $\mathrm{RSA}=24.7-258 \mu \mathrm{mol} \mathrm{TE} / 100 \mathrm{~g}$ and $\mathrm{TPC}=0.7-19.5 \mathrm{mg} / 100 \mathrm{~g}$ before and after thermal treatment, respectively) (Pellegrini et al. 2001; Kalantzakis et al. 2006).

The FRAP and FCI results of the studied oil samples significantly differ from each other (Duncan test, Table 1). This variability can be explained by the impact of genetic, environmental and technological factors and compositional difference in food samples, which can affect the antioxidants content.

On the other hand, FRAP $(28.0-56.7 \mu \mathrm{mol}$ TE/100 g) and FCI (198.3-376.5 $\mu \mathrm{mol} \mathrm{TE} / 100 \mathrm{~g})$ values of the processed meat samples were about 1.5 to six times higher than the results of antioxidant capacity for raw poultry meat (FRAP $=9.0 \mu \mathrm{mol} \mathrm{TE} / 100 \mathrm{~g}$ and $\mathrm{FCI}=135.7 \mu \mathrm{mol} \mathrm{TE} / 100 \mathrm{~g}$ ) and pork meat $(\mathrm{FRAP}=9.4 \mu \mathrm{mol} \mathrm{TE} / 100 \mathrm{~g}$ and $\mathrm{FCI}=$ $160.1 \mu \mathrm{mol} \mathrm{TE} / 100 \mathrm{~g}$ ) (Table 2). This fact can be explained by the fact that Maillard reaction products formed during heat treatment could act as antioxidants (Sacchetti et al. 2008; Gökmen et al. 2009). In addition to the naturally occurring antioxidants, frying may generate new antioxidants in processed meats which can be determined by FRAP and FC assays. Moreover, oils were absorbed on the surface of the prepared meat samples, and antioxidant components diffused from vegetable oils into meat samples. Duncan test indicated that raw poultry and pork meat samples did not differ significantly in FRAP results (Table 2). Somewhat higher FRAP values (13.8-22.5 $\mu \mathrm{mol} \mathrm{TE} / 100 \mathrm{~g}$ ) for beef meat samples were reported by Descalzo et al. (Descalzo et al. 2007; Descalzo and Sancho 2008). However, the lamb meat samples revealed about 5000 and 12500 times higher FRAP results (48000-113000 $\mu \mathrm{mol} / 100 \mathrm{~g}$ ) (Moñino et al.

Table 1 Antioxidant capacity of the studied vegetable oils

\begin{tabular}{|c|c|c|c|c|c|c|c|c|}
\hline \multirow[t]{3}{*}{ Sample } & \multicolumn{4}{|c|}{ FRAP $[\mu \mathrm{mol} \mathrm{TE} / 100 \mathrm{~g}]$} & \multicolumn{4}{|c|}{$\mathrm{FCI}[\mu \mathrm{mol} \mathrm{TE} / 100 \mathrm{~g}]$} \\
\hline & \multirow[t]{2}{*}{ Before frying } & \multicolumn{3}{|l|}{ After frying } & \multirow[t]{2}{*}{ Before frying } & \multicolumn{3}{|l|}{ After frying } \\
\hline & & Mpou & Mpor & $\mathrm{P}$ & & Mpou & Mpor & $\mathrm{P}$ \\
\hline RO & $149.6 \pm 1.4 \mathrm{c}, \mathrm{z}$ & $108.1 \pm 1.6 \mathrm{c}, \mathrm{y}$ & $48.6 \pm 0.2 \mathrm{a}, \mathrm{w}$ & $55.6 \pm 0.6 \mathrm{a}, \mathrm{x}$ & $156.2 \pm 0.9 \mathrm{~b}, \mathrm{z}$ & $83.9 \pm 0.9 b, y$ & $76.2 \pm 1.1 \mathrm{~b}, \mathrm{x}$ & $62.0 \pm 0.5 \mathrm{~b}, \mathrm{w}$ \\
\hline $\mathrm{PO}$ & $113.4 \pm 0.9 \mathrm{a}, \mathrm{z}$ & $49.1 \pm 0.3 \mathrm{a}, \mathrm{w}$ & $60.8 \pm 0.7 \mathrm{~b}, \mathrm{x}$ & $74.3 \pm 0.9 \mathrm{~b}, \mathrm{y}$ & $48.0 \pm 2.2 \mathrm{a}, \mathrm{z}$ & $16.5 \pm 0.7 \mathrm{a}, \mathrm{w}$ & $26.9 \pm 1.0 \mathrm{a}, \mathrm{x}$ & $29.8 \pm 1.5 \mathrm{a}, \mathrm{y}$ \\
\hline EVOO & $133.4 \pm 0.2 \mathrm{~b}, \mathrm{z}$ & $73.8 \pm 1.0 \mathrm{~b}, \mathrm{w}$ & $84.1 \pm 0.5 \mathrm{c}, \mathrm{x}$ & $119.0 \pm 1.3 \mathrm{c}, \mathrm{y}$ & $443.2 \pm 13.0 \mathrm{c}, \mathrm{z}$ & $171.1 \pm 3.3 \mathrm{c}, \mathrm{w}$ & $317.9 \pm 9.2 \mathrm{c}, \mathrm{x}$ & $343.0 \pm 14.5 \mathrm{c}, \mathrm{y}$ \\
\hline
\end{tabular}

Values are means \pm standard deviation, $n=9$. Different letters $(\mathrm{a}-\mathrm{c})$ within the same column indicate significant differences (one-way ANOVA and Duncan test, $p<0.05)$. Different letters $(\mathrm{w}-\mathrm{z})$ within the same row for FRAP and FCI results, respectively, differ significantly $(p<0.05)$

$F C I$ Folin-Ciocalteu Index, TE Trolox equivalent, $R O$ rapeseed oil, $P O$ palm oil, EVOO extra virgin olive oil, Mpou poultry meat, Mpor pork meat, $P$ potatoes 
Table 2 Antioxidant capacity of the meat and potato samples

\begin{tabular}{|c|c|c|c|c|c|c|c|c|}
\hline \multirow[t]{3}{*}{ Sample } & \multicolumn{4}{|c|}{ FRAP $[\mu \mathrm{mol}$ TE/100 g] } & \multicolumn{4}{|c|}{ FCI $[\mu \mathrm{mol} \mathrm{TE} / 100 \mathrm{~g}]$} \\
\hline & \multirow[t]{2}{*}{ Before frying } & \multicolumn{3}{|l|}{ After frying } & \multirow[t]{2}{*}{ Before frying } & \multicolumn{3}{|l|}{ After frying } \\
\hline & & RO & $\mathrm{PO}$ & EVOO & & RO & $\mathrm{PO}$ & EVOO \\
\hline Mpou & $9.0 \pm 0.2 \mathrm{a}, \mathrm{w}$ & $41.8 \pm 0.7 \mathrm{~b}, \mathrm{z}$ & $36.8 \pm 0.4 \mathrm{~b}, \mathrm{x}$ & $38.6 \pm 0.2 \mathrm{a}, \mathrm{y}$ & $135.7 \pm 1.3 \mathrm{a}, \mathrm{w}$ & $198.3 \pm 4.2 \mathrm{~b}, \mathrm{x}$ & $204.4 \pm 6.9 a, y$ & $376.5 \pm 2.6 \mathrm{c}, \mathrm{z}$ \\
\hline Mpor & $9.4 \pm 0.1 \mathrm{a}, \mathrm{w}$ & $31.1 \pm 0.4 \mathrm{a}, \mathrm{y}$ & $28.0 \pm 0.2 \mathrm{a}, \mathrm{x}$ & $56.7 \pm 0.6 \mathrm{~b}, \mathrm{z}$ & $160.1 \pm 3.7 \mathrm{~b}, \mathrm{w}$ & $270.1 \pm 4.9 \mathrm{c}, \mathrm{y}$ & $246.4 \pm 2.6 \mathrm{c}, \mathrm{x}$ & $359.2 \pm 14.5 b, z$ \\
\hline$P$ & $276.7 \pm 1.0 \mathrm{~b}, \mathrm{y}$ & $92.2 \pm 0.3 \mathrm{c}, \mathrm{x}$ & $75.4 \pm 1.3 \mathrm{c}, \mathrm{w}$ & $90.9 \pm 0.5 c, x$ & $342.9 \pm 7.4 \mathrm{c}, \mathrm{z}$ & $188.4 \pm 4.2 \mathrm{a}, \mathrm{w}$ & $236.7 \pm 4.8 \mathrm{~b}, \mathrm{x}$ & $255.0 \pm 10.2 \mathrm{a}, \mathrm{y}$ \\
\hline
\end{tabular}

Values are means \pm standard deviation, $n=9$. Different letters $(\mathrm{a}-\mathrm{c})$ within the same column indicate significant differences (one-way ANOVA and Duncan test, $p<0.05)$. Different letters $(\mathrm{w}-\mathrm{z})$ within same row for FRAP and FCI results, respectively, differ significantly $(p<0.05)$

FCI Folin-Ciocalteu Index, TE Trolox equivalent, RO rapeseed oil, PO palm oil, EVOO extra virgin olive oil, Mpou poultry meat, Mpor pork meat, $P$ potatoes

2008). Also, FRAP values of the discussed meat were about eight times lower when compared to FRAP results (77 $\mu \mathrm{mol} \mathrm{TE} / 100 \mathrm{~g}$ ) for raw pork meat obtained by LópezLópez et al. (López-López et al. 2009).

Moreover, frying process in the studied vegetable oils decreased the FRAP and FCI values of potatoes by about $70 \%$ and 25-45\%, respectively (Table 2). Also, ABTS value decreased by $29 \%$ for potatoes fried in vegetable oil (Ševčík et al. 2009). On the contrary, the quantity of raw potatoes needed to achieve $\mathrm{IC}_{50}$ was significantly higher (1078 $\mathrm{mg}$ ) than the amounts of French fries pan-fried in olive (15.2-54.0 mg), sunflower (19.9-57.2 mg) and palm (31.5-454 mg) oils before and after supplementation with olive leaf extract (Chiou et al. 2009).

The obtained values of RSD ranged between $0.14 \%$ and $4.98 \%$ indicating reasonable repeatability of the modified
FRAP and FC methods. For comparison, a significantly higher RSD value in determination of antioxidant capacity of unheated vegetable oils, meat and potato samples by FRAP method (0.34-33.05\%) was reported by others (Szydłowska-Czerniak et al. 2008a, b; Moñino et al. 2008; Descalzo et al. 2007; Descalzo and Sancho 2008; Lachman et al. 2009).

Correlation between Antioxidant Capacity of the Unprocessed and Processed Food Products Determined by Different Analytical Methods

Regression analysis was performed to calculate the correlation between FCI and FRAP results of the studied food products before and after frying process under domestic frying conditions. The linear and significant correlations a
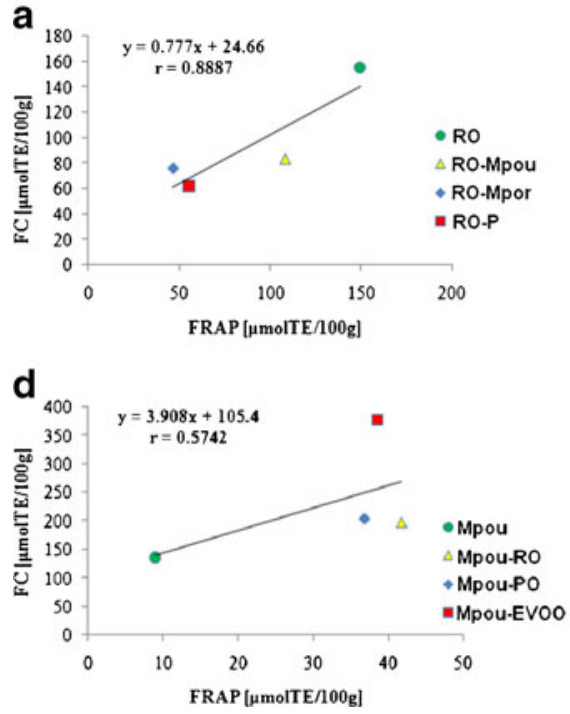

b
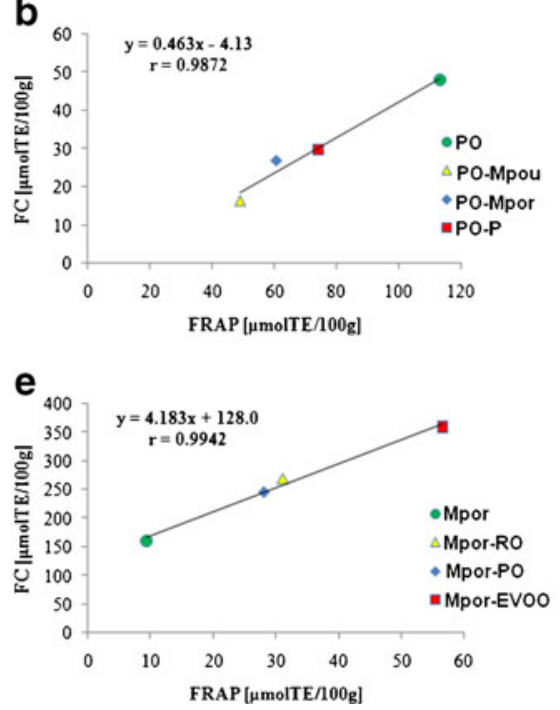

C
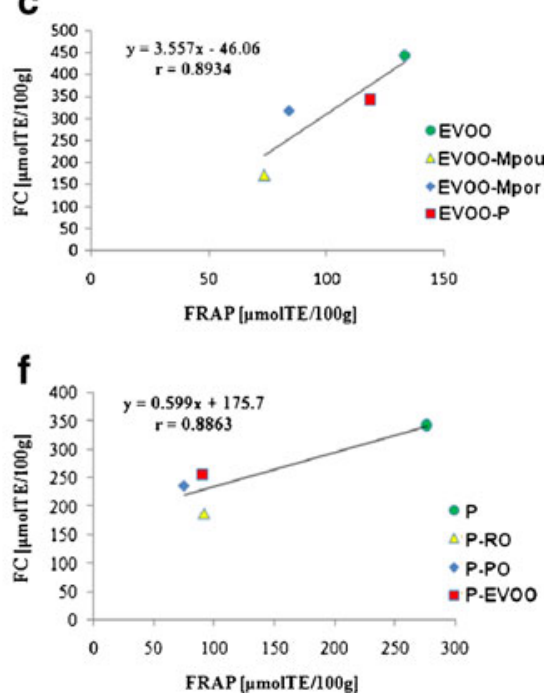

Fig. 1 Correlation between the FRAP and the FC methods for determination of antioxidant capacities of a unprocessed and processed rapeseed oils, b unprocessed and processed palm oils, c unprocessed and processed extra virgin olive oils, $\mathbf{d}$ unprocessed and processed poultry meat samples, e unprocessed and processed pork meat samples and $\mathbf{f}$ unprocessed and processed potatoes 
were found between the two analytical methods used to determine the antioxidant potential of unprocessed and processed palm oils and pork meat samples $(r=0.9872$ and $0.9942, p<0.05$, respectively) (Fig. 1b, e).

Besides, FRAP values for all studied rapeseed and extra virgin olive oils correlated with antioxidant capacity determined by the proposed FC method ( $r=$ 0.8887 and $0.8934, p>0.05$, respectively) (Fig. 1a, c). For comparison, positive linear correlation $(r=0.87)$ between total phenolics and radical-scavenging activity of unprocessed and processed olive oils analyzed by DPPH method was demonstrated by Silva et al. (Silva et al. 2010). Also, antioxidant capacity $\left(\mathrm{IC}_{50}\right)$ of the various vegetable oils after thermal treatment correlated with polyphenolic content in the methanolic fraction of these oils (Valavanidis et al. 2004). However, the lowest correlation coefficient $(r=0.5742)$ was observed between FCI and the FRAP results of raw and processed poultry meat samples in three different edible oils (Fig. 1d). The latter can be explained by the fact that reducing species formed during cooking of poultry meat do not exhibit the ferric-reducing ability. On the contrary, a linear but insignificant correlation $(r=0.8863)$ was found between FCI and FRAP results of raw and fried potatoes (Fig. 1f). These correlations confirm the usefulness of FolinCiocalteu reducing capacity method for the assessment of total antioxidant capacity of food samples. Similar correlation $(r=0.952)$ was found by López-López et al. for the polyphenolic amounts in the meat emulsion systems and their antioxidant capacity determined in the acid methanol/acetone extracts by the FRAP assay (López-López et al. 2009).
Principal Component Analysis

Principal component analysis (PCA) was applied to observe any possible clusters within analyzed oils, meats and potatoes before and after the frying process under domestic frying conditions. The first two principal components took into account $100 \%(\mathrm{PC} 1=63.54 \%$ and $\mathrm{PC} 2=36.46 \%$, respectively) of the total variation. The scores of the first two principal components for 24 studied food products are presented in Fig. 2.

A PCA graph reveals that the unprocessed meat samples and fried food products with low antioxidant capacities are located to the left in the score plot, whereas unheated rapeseed and olive oils, raw and fried potatoes, olive oils after prepared with the studied food products and cooked meats in olive oils with higher FRAP and FCI values are situated at the right in the diagram. It is noteworthy that the studied food products fell into eight distinct groups, respectively, whereas raw potatoes $(\mathrm{P})$, unheated rapeseed oil (RO) and extra virgin olive oil (EVOO) were clearly separated from these groups (Fig. 2). These food groups generally have a similar antioxidant capacity. The unprocessed potatoes $(\mathrm{P})$ with the longest distance from other food samples had the highest value of FRAP $=276.7 \mu \mathrm{mol}$ TE/100 g, while the highest FCI $(443.2 \mu \mathrm{mol} \mathrm{TE} / 100 \mathrm{~g})$ was determined for extra virgin olive oil (EVOO) before thermal treatment (Fig. 2, Table 1). It can be observed that raw poultry and pork meats with similar FRAP and FCI values and meat samples prepared in all studied vegetable oils are situated in the individual groups. However, there is a long distance between the processed extra virgin olive oils with high level of antioxidants, and rapeseed and palm oils
Fig. 2 Score plot of first two principal components ( $\mathrm{PC} 1$ and $\mathrm{PC} 2)$ for the classification of unprocessed and processed food products

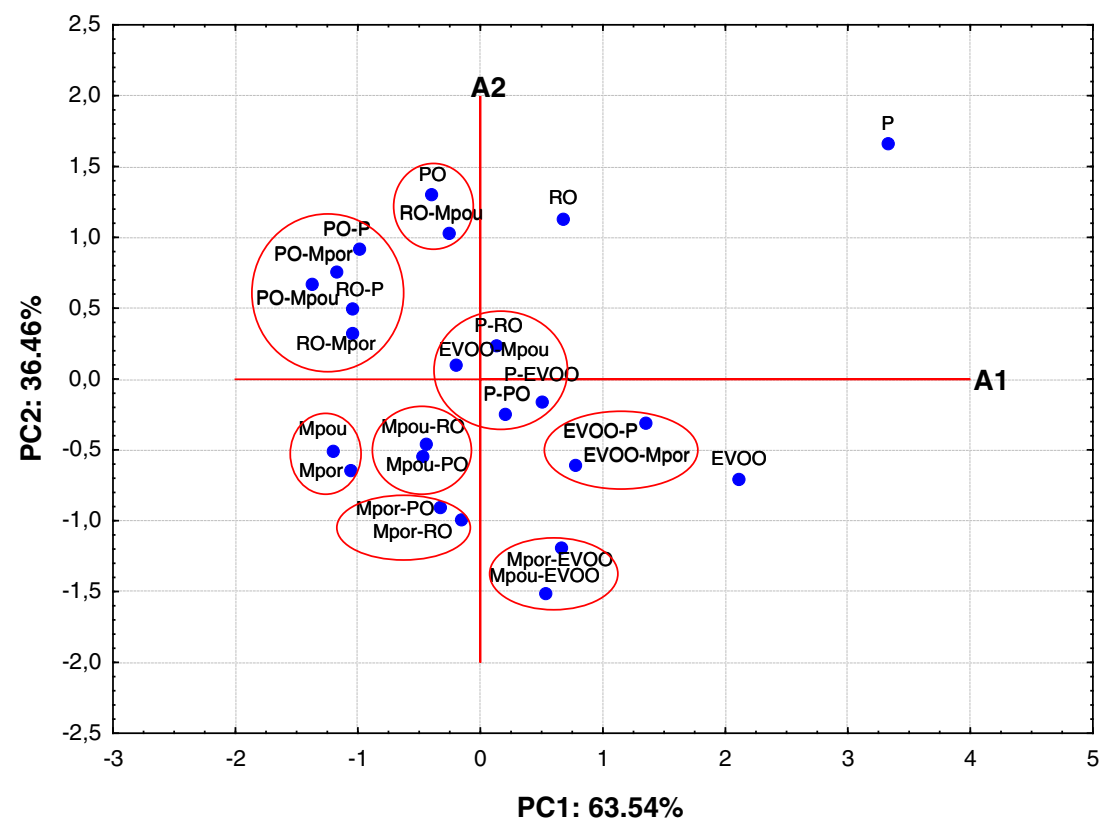


after frying meats and potatoes. Also, frying process of potatoes in each of the tested edible oils did not change significantly their antioxidant potential. Thus, the fried potatoes as well as extra virgin olive oil after frying poultry meat with a similar level of antioxidant created a separate cluster (Fig. 2).

\section{Conclusions}

The proposed FRAP and FC methods are relatively simple, precise and convenient for the determination of antioxidant capacity of food products before and after frying process. Moreover, FRAP results for the unprocessed and processed food samples correlated with total reducing capacity determined by the Folin-Ciocalteu assay. The frying processes of food products under domestic frying conditions caused the decreasing of antioxidant capacity of vegetable oils and potatoes. However, the fried poultry and pork meat samples revealed higher antioxidant potential than raw meats. Therefore, it can be considered that the Maillard reactions products generated in the processed meats have antioxidative activities.

The modified FRAP and FC methods can be usefully employed by the food industry in assessing the antioxidant capacity of different unprocessed and processed food products.

Open Access This article is distributed under the terms of the Creative Commons Attribution Noncommercial License which permits any noncommercial use, distribution, and reproduction in any medium, provided the original author(s) and source are credited.

\section{References}

Benzie IFF, Strain JJ (1996) Anal Biochem 239:70

Blessington T, Nzaramba MN, Scheuring DC, Hale AL, Reddivari L, Miller Jr JC (2010) Am J Pot Res 87:479

Cheung SChM, Szeto YT, Benzie IFF (2007) Plant Food Hum Nutr 62:39
Chiou A, Kalogeropoulos N, Salta FN, Efstathiou P, Andrikopoulos NK (2009) LWT- Food Sci Technol 42:1090

Descalzo AM, Rossetti L, Grigioni G, Irurueta M, Sancho AM, Carrete J, Pensel NA (2007) Meat Sci 75:299

Descalzo AM, Sancho AM (2008) Meat Sci 79:423

Farhoosh R, Kenari RE, Poorazrang H (2009) J Am Oil Chem Soc $86: 71$

Gökmen V, Serpen A, Fogliano V (2009) Trends Food Sci Tech 20:278

Gupta MK (2005) Bailey's Ind. Oil Fat Prod 6:1

Hay KX, Waisundara VY, Timmins M, Ou B, Pappalardo K, Mchale N, Huang D (2006) J Agr Food Chem 54:5299

Jung S, Choe JH, Kim B, Yun H, Kruk ZA, Jo C (2010) Meat Sci $86: 520$

Kalantzakis G, Blekas G, Pegklidou K, Boskou D (2006) Eur J Lipid Sci Tech 108:329

Lachman J, Hamouz K, Šulc M, Orsák M, Pivec V, Hejtmánková A, Devořák P, Čepl J (2009) Food Chem 114:836

López-López I, Bastida S, Ruiz-Capillas C, Bravo L, Larrea MT, Sánchez-Muniz F, Cofrades S, Jiménez-Colmenero F (2009) Meat Sci 83:492

Moñino I, Martínez C, Sotomayor JA, Lafuente A, Jordán MJ (2008) J Agr Food Chem 56:3363

Napolitano A, Morales F, Sacchi R, Fogliano V (2008) J Agr Food Chem 56:2034

Pellegrini N, Visioli F, Buratti S, Brighenti F (2001) J Agr Food Chem 49:2532

Rautenbach F, Venter I (2010) J Food Compos Anal 23:753

Sacchetti G, Mattia CD, Pittia P, Martino G (2008) Meat Sci 80:1081

Ševčík R, Kondrashov A, Kvasnička F, Vacek J, Hamouz K, Jirušková M, Voldřich M, Č́žková H (2009) J Food Nutr Res 48:171

Silva L, Pinto J, Carrola J, Paiva-Martins F (2010) Food Chem 121:1177

Singleton VL, Rossi JA (1965) Am J Enol Viticult 16:144

Szydłowska-Czerniak A, Dianoczki C, Recseg K, Karlovits G, Szłyk E (2008a) Talanta 76:899

Szydłowska-Czerniak A, Karlovits G, Dianoczki C, Recseg K, Szłyk E (2008b) J Am Oil Chem Soc 85:141

Teow ChC, Truong V-D, McFeeters RF, Thompson RL, Pecota KV, Yencho GC (2007) Food Chem 103:829

Tuberoso CIG, Kowalczyk A, Sarritzu E, Cabras P (2007) Food Chem 103:1494

Valavanidis A, Nisiotou C, Papageorgiou Y, Kremli I, Satravelas N, Zinieries N, Zygalaki H (2004) J Agr Food Chem 52:2358

Wu C, Duckett SK, Neel JPS, Fontenot JP, Clapham WM (2008) Meat Sci 80:662 